\title{
The risk of osteoporosis in oral steroid treatment for nasal polyposis: a systematic review*
}

\author{
Lisa Winblad', Christian Grønhøj Larsen', Kåre Håkansson', Bo Abrahamsen², \\ Christian von Buchwald' \\ Department of Otorhinolaryngology, Head and Neck Surgery and Audiology, Rigshospitalet Copenhagen University Hospital, \\ Copenhagen, Denmark \\ Department of Medicine, Holbæk Hospital, DK-4300 Holbæk. Odense Patient Data Explorative Network, University of Southern \\ Denmark and Odense University Hospital, DK-5000 Odense C, Denmark
}

Rhinology 55: 195-201, 2017

https://doi.org/10.4193/Rhino15.367

*Received for publication:

December 9, 2015

Accepted: November 8, 2016

\begin{abstract}
Background: Systemic glucocorticoids are often used in the treatment of chronic rhinosinusitis with nasal polyps (CRSwNP), and osteoporosis is a well-known complication to steroid treatment, associated with significant morbidity. Nevertheless, the burden of steroid induced osteoporosis is unknown in patients with CRSwNP. We aimed to assess the risk of acquiring osteoporosis caused by oral steroids in patients with CRSWNP, and provide recommendations on future research and guidelines.
\end{abstract}

Methodology: Cochrane Review Database, EMBASE, Ovid Medline, and PubMed were searched for studies including adult patients with CRSwNP treated with oral steroids. Outcomes were Bone Mineral Density (BMD) and prevalence of fractures in relation to dose and duration of oral steroids. In addition, we reviewed general guidelines for treatment with oral steroids.

Results: We identified two studies ( $n=243$ ) that met the inclusion criteria. Doses and durations of oral steroids were $>5 \mathrm{mg} / \mathrm{day}$ for $\geq 3$ months and $1 \mathrm{mg} / \mathrm{kg}$ body weight/day for 6 to 10 days for $\geq 4$ courses/year. The prevalence of low bone mass was $39 \%$ and $61 \%$, respectively. It was not possible to quantify the overall risk of osteoporosis induced by oral steroids from the studies. No studies evaluated prevalence of fracture.

Conclusions: Registry studies and randomized controlled trials would be needed to assess the risk of osteoporosis in CRSwNP patients and future guidelines should include recommendations regarding preventive treatment and recommendations on doses and durations of oral steroids.

Key words: nasal polyps, asthma, oral steroids, osteoporosis, fractures

\section{Introduction}

Treatment with oral glucocorticoids is common for patients with nasal polyps (NP, also named chronic rhinosinusitis with polyps, CRSwNP) with or without asthma ${ }^{(1)}$. A commonly suggested regimen for adults is $0.5-1.0 \mathrm{mg} / \mathrm{kg}$ of prednisolone or prednisolone equivalent daily for 5-14 days, in combination with a topical nasal steroid ${ }^{(1,2)}$. According to EPOS2012, a short course of oral steroids improves symptoms and causes reductions in polyp size and should be considered for severe NP ${ }^{(3)}$. However, oral steroids cause several adverse effects; here amongst disruption of the hypothalamic-pituitary-adrenal axis, hyperglycemia and glucose intolerance, gastrointestinal ulcer and osteoporosis ${ }^{(3,4)}$.
The percentage of CRSwNP patients treated with systemic steroids and the burden of osteoporosis in these patients is unknown. However, this adverse effect of systemic steroids is well known from studies of other patient categories. One of these studies suggests that the current population at risk of developing glucocorticoid-induced fractures in the UK may be as large as 350,000 individuals, and that the vast majority of these individuals have not been evaluated for the risk of osteoporosis, or received preventive treatment ${ }^{(5)}$. In accordance with this, we expected to find an increased prevalence of osteoporosis in patients with CRSwNP treated with systemic steroids.

Osteoporosis is a systemic skeletal disease characterized by low 
bone density resulting in decreased bone strength, increased bone fragility and consequently risk of fracture ${ }^{(6)}$. Osteopenia and osteoporosis are defined according to $\mathrm{WHO}$ and quantified by T-score. The diagnosis can be made based on a T-score more than 2.5 SD below young adult mean at the spine or hip, or on the existence of low energy fractures that are not explained by other disorders of bone, such as bone metastases. We aimed to assess the existing literature on the risk of osteoporosis from oral glucocorticoids in patients treated for NP with or without asthma. We believe this is the first systematic review assessing oral glucocorticoids and the risk of osteoporosis in patients with CRSwNP.

\section{Materials and methods}

In May 2016, one author (LW) searched the Cochrane Database, EMBASE, Ovid Medline, and PubMed using the key words: "Nasal Polyps" AND "Steroids" AND ("Osteoporosis" OR "Osteopenia" OR "Fractures") with suggested MeSH-terms. The optimal search criteria were defined by two previous searches in March 2015 and October 2015. Inclusion criteria were studies of adults with CRSwNP with or without concomitant asthma treated with systemic steroids including an assessment of the risk of low bone mass. Exclusion criteria were studies evaluating patients with allergic fungal sinusitis, Churg Strauss syndrome or Cystic Fibrosis. The following data were extracted: demographics, oral steroid dose, BMD (T-and Z-scores), nasal symptoms and preventive treatment. All studies were assessed for the risk of bias using "The Cochrane Collaboration's tool for assessing risk of bias" (7). Finally, we retrieved guidelines for the management of NP and treatment with oral steroids.

\section{Results}

We identified 14 eligible trials from which two $(n=243)$ met the inclusion criteria. The trials were conducted between 1990 and 2015 (Figure 1, Tables 1, 2).

A retrospective, uncontrolled trial $(n=197)$ evaluated the degree of osteoporosis in patients with chronic rhinosinusitis (CRS) with nasal polyps ( $n=176)$ and without nasal polyps $(n=21) ; 81.7 \%$ had concomitant asthma ${ }^{(8)}$. Participants had been DXA scanned less than five years prior to inclusion and had taken oral steroids ( $>5 \mathrm{mg}$ daily) for at least three months before inclusion, which is much longer than the commonly suggested treatment with short courses of 5-14 days. The study does not provide information about the exact amount of oral steroids that each patient had consumed. The included patients received preventive treatment in the form of bisphosphonates (50.3\%), calcium (82.7\%), vitamin D (83.8\%) and estrogen (10.7\%). The DXA was performed at three sites; the lumbar spine, the femoral neck and the total hip. High rates of osteopenia, osteoporosis or low bone density (LBD) at the lumbar spine site were reported and

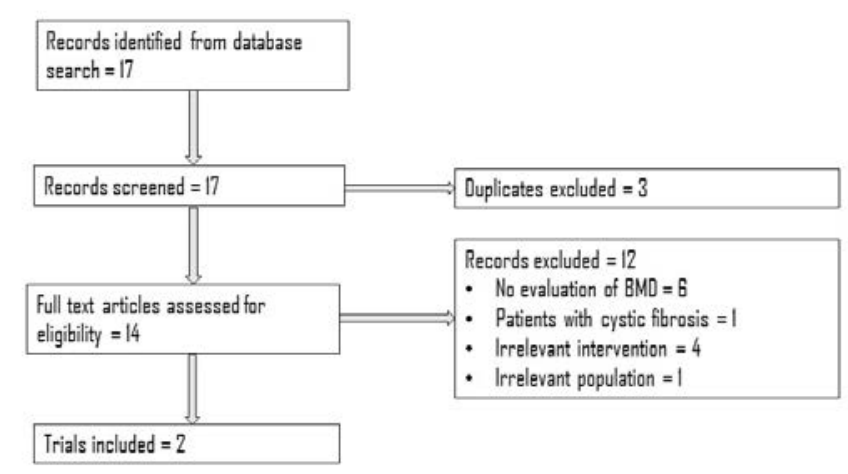

Figure 1. Search strategy.

the prevalence of LBD or osteopenia/osteoporosis was overall $38.6 \%$. The older patient groups had a greater prevalence of osteopenia/osteoporosis or LBD ( $p<0.0001)$, and the study showed insignificant differences between men and women. The study concluded that cumulative steroid doses correlated strongly with loss of bone density, regardless of age, gender, and underlying disease. Consequently, this effect could be more problematic in younger patients who will be at higher risk of bone loss with accruing doses of oral steroids. However, this recommendation is not substantiated in the study, since the study does not cover accumulated doses during lifetime.

A prospective, uncontrolled trial $(n=46)$ studied osteoporosis after oral steroid treatment in patients with CRSwNP (associated with asthma and/or aspirin intolerance) ${ }^{(9)}$. This study is an extension of a trial by Nores et al. ${ }^{(10)}$ with partly the same patient population. Patients had taken at least four courses of oral steroid during the past 12 months. Each course consisted of prednisolone $1 \mathrm{mg} / \mathrm{kg}$ body weight/day for 6 to 10 days. This would indicate a cumulative dose as high as $600 \mathrm{mg}$ of oral steroid for a $60 \mathrm{~kg}$ patient per ten-day course.

The mean duration of treatment was 4.7 years $(S D=4.2$, range 1-22). The mean number of oral steroid courses per year was 6.8 $(S D=4.7$, range 4-26). The study only mentions the number of postmenopausal women $(n=7)$ but no further details are given on demographics. There is no information about preventive treatment despite the high steroid dosage. A DXA scan was carried out at least once for each patient and the T-score was calculated for three different sites; lumbar spine, femoral neck and proximal femur. The study showed a high prevalence of osteoporosis and osteopenia (12.2\% and $48.8 \%$, respectively) at the lumbar spine, compared to the normal population as referenced in the study. In conclusion, the patients with severe NP and a high steroid consumption had a high prevalence of steroid induced osteoporosis.

Risk of bias in the included studies

Rajasekaran et al. studied patients recruited from tertiary care; 
Table 1. Demographic data of patients in the two included studies of CRSWNP.

\begin{tabular}{|c|c|c|c|c|c|c|c|}
\hline Study & Country & $\begin{array}{l}\text { Years of } \\
\text { collection }\end{array}$ & $\begin{array}{l}\text { Total number of } \\
\text { patients }\end{array}$ & $\begin{array}{l}\text { Mean age in the } \\
\text { intervention } \\
\text { group (range/ } \\
\text { SD) }\end{array}$ & Males & Females & Ethnicity \\
\hline $\begin{array}{l}\text { Rajasekaran et al. } \\
2010^{(8)}\end{array}$ & USA & $2003-2008$ & $\begin{array}{l}197 \text { with CRSsNP }{ }^{1} \\
176 \text { with CRSwNP }\end{array}$ & $\begin{array}{c}51.1 \\
\text { (range 15-79) }\end{array}$ & $n=108$ & $\mathrm{n}=89$ & $\begin{array}{l}\text { White: } 170 \\
\text { Black: } 19 \\
\text { Hispanic: } 1 \\
\text { Unknown: } 7\end{array}$ \\
\hline Bonfils et al. $2006^{(9)}$ & France & 2006 & 46 with CRSwNP & $49.4(\mathrm{SD}=10.8)$ & $n=26$ & $\mathrm{n}=20$ & \\
\hline
\end{tabular}

${ }^{1}$ CRSsNP= Chronic rhinosinusitis without nasal polyps

Table 2. Comparison between treatments for CRSwNP and treatment with short courses for other diseases.

\begin{tabular}{|c|c|c|c|c|c|c|c|c|}
\hline Study & Design & $\begin{array}{c}\text { Number } \\
\text { of pa- } \\
\text { tients }\end{array}$ & $\begin{array}{l}\text { Oral steroids } \\
\text { protocol }\end{array}$ & $\begin{array}{l}\text { Asth- } \\
\text { ma \% }\end{array}$ & $\begin{array}{l}\text { Clinical } \\
\text { outcome }\end{array}$ & $\begin{array}{l}\text { Prevalence } \\
\text { of LBD/ } \\
\text { osteoporo- } \\
\text { sis/ } \\
\text { osteopenia }\end{array}$ & $\begin{array}{c}\text { Preventive } \\
\text { treatment } \\
\text { before/dur- } \\
\text { ing trial }\end{array}$ & Conclusion \\
\hline $\begin{array}{l}\text { Rajasekaran } \\
\text { et al. 2010 } \\
\text { (CRSwNP) }\end{array}$ & $\begin{array}{l}\text { Retrospec- } \\
\text { tive }\end{array}$ & 197 & $\begin{array}{l}>5 \mathrm{mg} / \text { day } \\
>3 \text { months }\end{array}$ & 82 & $\begin{array}{l}\text { LBD/ } \\
\text { osteopo- } \\
\text { rosis/ oste- } \\
\text { openia }\end{array}$ & $39 \%$ & $\begin{array}{l}\text { Bisphosp- } \\
\text { honates, } \\
\text { calcium, } \\
\text { vitamin D and } \\
\text { estrogen }\end{array}$ & $\begin{array}{l}\text { Cumulative steroid doses } \\
\text { correlated strongly with loss } \\
\text { of bone density, regardless of } \\
\text { age, gender, and underlying } \\
\text { disease. }\end{array}$ \\
\hline $\begin{array}{l}\text { Bonfils } \\
\text { et al. } 2006^{(9)} \\
\text { (CRSwNP) }\end{array}$ & $\begin{array}{l}\text { Prospec- } \\
\text { tive }\end{array}$ & 46 & $\begin{array}{l}1 \mathrm{mg} / \mathrm{kg} / \mathrm{day} \text {, } \\
6-10 \text { days. } \\
\text { Mean number of } \\
\text { oral steroid courses } \\
\text { was } 6.8 / \text { year }\end{array}$ & 78 & $\begin{array}{l}\text { Low BMD, } \\
\text { adrenal } \\
\text { function }\end{array}$ & $61 \%$ & $\begin{array}{l}\text { No informa- } \\
\text { tion }\end{array}$ & $\begin{array}{l}\text { Patients with severe NP and } \\
\text { a high steroid consumption } \\
\text { had a high prevalence of ste- } \\
\text { roid induced osteoporosis. }\end{array}$ \\
\hline $\begin{array}{l}\text { Matsumoto } \\
\text { et al. } 2001^{(12)} \\
\text { (Asthma) }\end{array}$ & $\begin{array}{l}\text { Longitu- } \\
\text { dinal }\end{array}$ & 35 & $\begin{array}{l}20-40 \mathrm{mg} / \text { day for } \\
\text { 3-14 days. } \\
1.9 \pm 2.7 \text { courses/ } \\
\text { year (mean } \pm S D \text { ) }\end{array}$ & 100 & Low BMD & $56 \%$ & $\begin{array}{l}\text { No preventive } \\
\text { treatment }\end{array}$ & $\begin{array}{l}\text { Significantly greater loss in } \\
\text { BMD in }>2.5 \text { courses per year } \\
\text { compared with } \leq 2.5 \text { courses } \\
\text { per year. }\end{array}$ \\
\hline
\end{tabular}

therefore, patients with a more severe disease were selected over other patients ${ }^{\left({ }^{8}\right)}$. In addition, recall bias and selection bias must be considered due to inclusion of patients with a previous DXA scan. Finally, the study was uncontrolled.

The study by Bonfils et al. was also uncontrolled and fails to describe from where and how patients were recruited ${ }^{(9)}$. This unusually high number of oral steroid courses may indicate that the patients treated in this study were selected. Furthermore, there is no information of previous DXA scans and it is unclear whether the patients had low BMD before the therapy started, (Table 3).

\section{Discussion}

The aim of this study was to review the literature on the risk of osteoporosis in CRSwNP patients taking oral glucocorticoids. The two studied trials, both with considerable bias, concluded that oral steroids increase osteoporosis in patients with CRSwNP. The limited available data and the high risk of bias entails that the studies are too heterogeneous to enable a meta-analysis. Rajasekaran et al. reported that men $>50$ years of age and postmenopausal women had a statistically higher prevalence of osteoporosis or LBD when compared with younger men and premenopausal women ${ }^{(8)}$. This result was adjusted for age and sex. The possibility that older patients may have received higher doses or durations of oral steroids compared to the younger patients was unverified. There was no sex difference, which is surprising, as women generally have a higher prevalence of osteoporosis than men. Many of the included patients had received preventive treatment before the trial but there was no information on how this may have influenced the results or if this is the reason for the absence of the expected gender difference.

Bonfils et al. reported osteopenia or osteoporosis at the lumbar spine in $61.0 \%$ patients with NP ( 25 patients of 41 with an abnormal T-score at the lumbar spine) ${ }^{(9)}$. This is a remarkable high prevalence of osteoporosis compared to the prevalence of osteoporosis in the US population: $10 \%$ of Americans over age 50 are estimated to have osteoporosis ${ }^{(11)}$. The given doses correspond to $480 \mathrm{mg}$ per course for a $60 \mathrm{~kg}$ patient during an 
Table 3. Risk of bias in the two included CRSwNP studies.

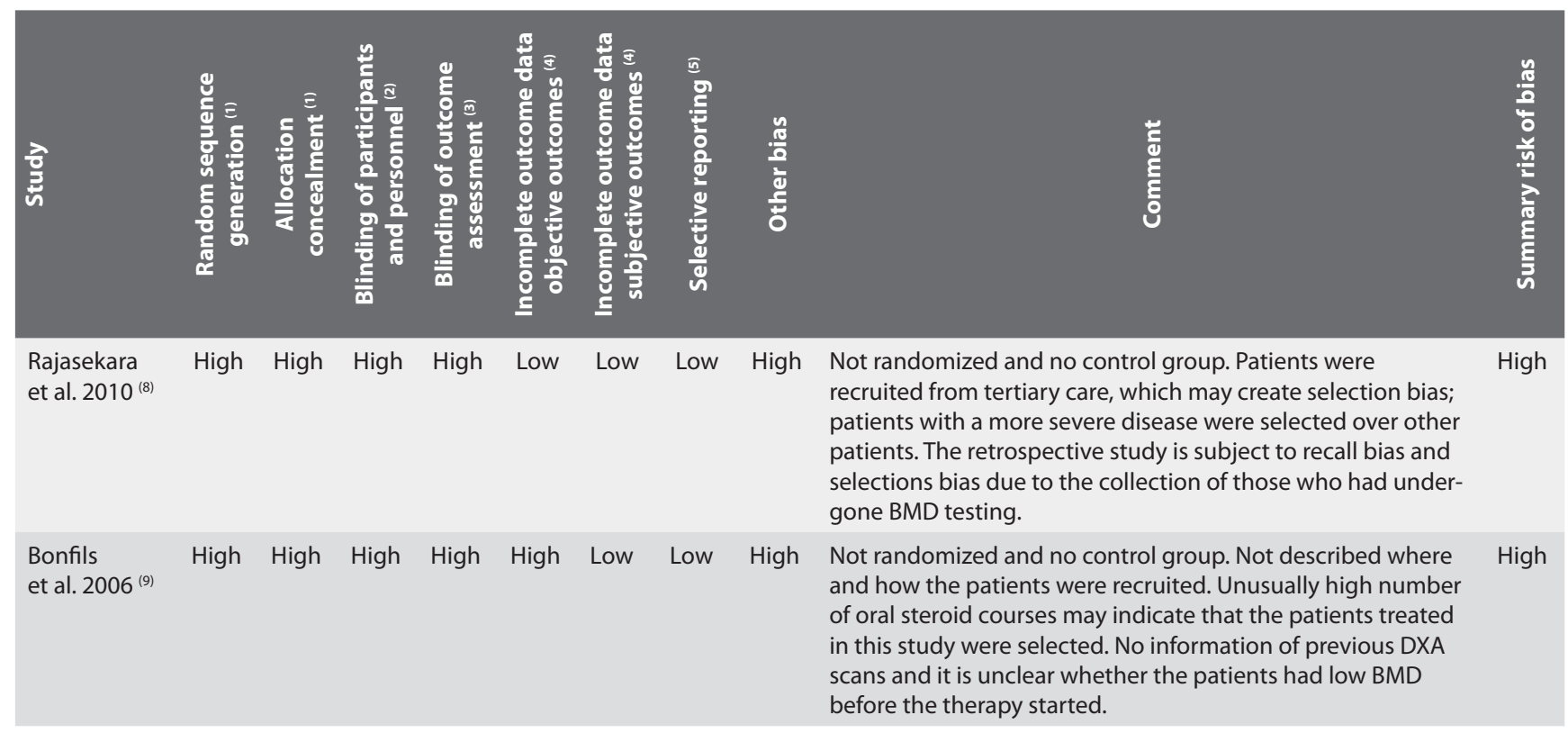

${ }^{1}$ Selections bias; ${ }^{2}$ Performance bias; ${ }^{3}$ Detections bias; ${ }^{4}$ Attritions bias; ${ }^{5}$ Reporting bias.

Table 4. A summary of the studied guidelines. Guidelines for preventive treatment of glucocorticoid induced osteoporosis, not specifically related to CRSWNP.

\begin{tabular}{|c|c|c|c|c|}
\hline Variable & $\begin{array}{l}\text { Bone and Tooth Society of } \\
\text { Great Britain }{ }^{(5)}\end{array}$ & $\begin{array}{l}\text { National Osteoporosis } \\
\text { Foundation (6) }\end{array}$ & $\begin{array}{l}\text { American College of } \\
\text { Rheumatology }{ }^{(16)}\end{array}$ & Danish Bone Society ${ }^{(17)}$ \\
\hline Sex, age (years) & $\begin{array}{l}\text { Men and women } \\
\text { Children and adult }\end{array}$ & $\begin{array}{l}\text { Postmenopausal women } \\
\text { and men }>50\end{array}$ & $\begin{array}{l}\text { Men and women } \\
\geq 18\end{array}$ & $\begin{array}{l}\text { Men and women } \\
\geq 18\end{array}$ \\
\hline $\begin{array}{l}\text { Dose and duration of oral } \\
\text { steroids before considering } \\
\text { preventive treatment }\end{array}$ & Not specified & $\geq 5 \mathrm{mg} /$ day for $>3$ months & $\begin{array}{l}\text { All doses expected to be } \\
\text { used for }>3 \text { months }\end{array}$ & $5 \mathrm{mg} /$ day for 3 months \\
\hline $\begin{array}{l}\text { BMD threshold* before } \\
\text { considering preventive } \\
\text { treatment }\end{array}$ & $<-1.5$ & $\begin{array}{l}-2.5(-1.0 \text { in postmenopau- } \\
\text { sal women and men }>50)\end{array}$ & Overall clinical risk profiles & $<-1$ \\
\hline BMD follow up & Yearly & $\begin{array}{l}\text { After } 1 \text { to } 2 \text { years and every } \\
2 \text { years thereafter }\end{array}$ & Yearly & After $1-2$ years \\
\hline Daily calcium & For all & $1200 \mathrm{mg}$ & $1200-1500 \mathrm{mg}$ & $800-1200 \mathrm{mg}$ \\
\hline Daily vitamin D & For all & $1000 \mathrm{IU}$ & $800-1000$ IU & $800 \mathrm{IU}$ \\
\hline $\begin{array}{l}\text { Bisphosphonates recom- } \\
\text { mended }\end{array}$ & Yes & Yes & Yes & $\begin{array}{l}\text { Yes, and parathyroid } \\
\text { hormone for those with } \\
\text { T-score }<-2.5\end{array}$ \\
\hline
\end{tabular}

8-day course, which corresponds to an accumulated yearly dose of almost $2000 \mathrm{mg}$. The high prevalence of osteoporosis may be related to the unusual high doses and durations of oral steroids which may indicate that the patients treated in this study had severe CRSWNP and it is unclear if the outcome of this trial is relevant for patients taking fewer courses per year. Information on demographics and underlying diseases would have increased the understanding of the results of the Bonfils et al. study. Due to the limited number of trials found, we compared guide- lines for prevention of corticosteroid-induced osteoporosis in other diseases (Table 4).

A commonly suggested regimen for adults with CRSwNP is $0.5 \mathrm{mg} / \mathrm{kg}$ daily for $5-10$ days ${ }^{(1,2)}$. There is only scant information on the effect on BMD and the risk of fractures associated with courses of that duration. However, in a study of patients who received high doses of oral steroids (20 to $40 \mathrm{mg}$ daily) for a similar duration (3-14 days), a significantly greater loss in 
Table 5. Risk factors that contribute to osteoporosis and fractures.

Risk factor
High intake of oral glucocorticoids ${ }^{(6,12,16)}$
$\quad 25$ mg/day of prednisone for $\geq 3$ months ${ }^{(6)}$
or high cumulative glucocorticoid dose ${ }^{(16)}$
or $>2.5$ short courses per year, $\left(20-40\right.$ mg glucocorticoid $^{(12)}$
for $3-14$ days)
Age ${ }^{(6)}$
$\quad$ Women $>65$ years
Men $>70$ years
Prior osteoporotic fracture ${ }^{(6)}$
Low body mass index ${ }^{(6,16)}$
Parental history of hip fracture ${ }^{(6,16)}$
Smoking ${ }^{(6,15)}$
Excessive alcohol consumption ${ }^{(6,16)}$
$\geq 3$ drinks/day
Femoral neck BMD ${ }^{(6)}$
Vitamin D insufficiency ${ }^{(6)}$

BMD was seen in patients receiving $>2.5$ courses per year $(n$ $=9$ ) compared with those receiving sporadic courses, i.e. $\leq 2.5$ courses per year $(n=26)^{(12)}$. From this we conclude that infrequent usage $(<2.5$ per year) probably is safe, while 3 or more courses per year would be considered indicative of uncontrolled disease and would indicate that surgery or other interventions may be required. A daily dose of $\geq 30 \mathrm{mg}$ and a cumulative exposure of $>5000 \mathrm{mg}$, has been shown to increase the risk of osteoporotic fracture substantially, while first-time use with an average duration of 10 days of high-dose glucocorticoid therapy ( $\geq 30 \mathrm{mg}$ ) was associated with only a small increased risk of osteoporotic fracture ${ }^{(13)}$.

In a meta-analysis, Van Staa et. al. conclude that the daily rather than the cumulative, dose of glucocorticoids was found to be a strong predictor of vertebral fracture in patients receiving oral steroids ${ }^{(14)}$. This is in contrast to recommendations in the studied guidelines where the cumulative dose is considered to be the most important factor for preventive therapy. At similar levels of BMD, postmenopausal women taking oral steroids, as compared with controls, had considerably higher risks of fracture. There was not enough data to establish whether the intervention threshold should be a T-score of -1.0 or -1.5 . The study also supported the hypothesis that treatment with oral steroids influences the occurrence of fracture by a mechanism independent of BMD. Vestergaard et al. found that oral prednisolone/ prednisone was associated with a dose-dependent increase in fracture risk starting from a dose of 7.6- $10 \mathrm{mg}$ /day even with a duration of $<60$ days ${ }^{(15)}$.
We did not find any reports indicating that the adverse effects of oral steroids should be different in CRSwNP patients than in patients treated for other diseases. Thus we reviewed general guidelines for glucocorticoid-induced osteoporosis, not specifically related to CRSWNP and we believe that these guidelines may also support future recommendations for CRSwNP (Table 4). The recommended preventive treatment varies greatly between the guidelines, and there is sparse information on how to maintain satisfying results. Although the greatest increase in risk is observed with higher dose therapy, increased risk is reported with doses as low as $2.5 \mathrm{mg}$ daily of oral steroids after three months of treatment while other studies report an increased risk at $7.5 \mathrm{mg}$ daily ${ }^{(5)}$. Clearly, the risk of bone fracture is increased by oral steroids as a result of induced osteoporosis. In addition to this effect, however, oral steroid may also cause low energy fractures by a mechanism unrelated to bone decalcification. It has been suggested, although not confirmed in recent studies that glucocorticoid-induced fractures occur at a higher BMD than in age-related or postmenopausal osteoporosis. Therefore, the studied guidelines recommend preventive treatment at a higher T-score $(<-1 \text { or }<-1.5)^{(5,6,16,17)}$. A yearly DXA scan and life style counselling including regular muscle-strengthening exercises are recommended ${ }^{(5,6)}$. A follow-up of patients receiving any dose of oral steroids and a fall risk assessment is recommended as well as an evaluation for prevalent fragility fractures and a vertebral fracture assessment or radiographic imaging of the spine ${ }^{(16)}$. A DXA scan is suggested at doses of $37.5 \mathrm{mg}$ oral steroids for 10 days and should be carried out before the treatment and a follow up is recommended after two years regardless of dose and duration ${ }^{(14)}$. Patients with fragility fracture or with one or more risk factors for osteoporosis treated with oral steroids equivalent to prednisolone $>5 \mathrm{mg}$ daily for more than 3 months should also be DXA scanned ${ }^{(17)}$ (Table 5).

Common for these guidelines is that they recommend DXA scan at intervals of 1-2 years, as well as a diet with adequate levels of calcium and vitamin $D$, and this is generally regarded as supplements to other treatments. Bisphosphonates, as the primary anti-resorptive agent are recommended by all the studied guidelines; however, other treatments are also mentioned (Selective Estrogen Receptor Modulating substances, Strontium ranelate and Denosumab) and bone anabolic agents (Parathyroid hormone analogues).

Of the searched guidelines for 1) the management of CRSwNP and 2) for osteoporosis prevention induced by oral steroids, no in depth recommendations was identified for patients with CRSwNP. The recommendations found in EPOS2012 included follow-up strategies for patients with CRSwNP and general recommendations to observe the risk of osteoporosis as well as regular calcium and vitamin D supplements ${ }^{(3)}$. A DXA scan every two years is worth considering. 


\section{Further research}

We propose that registry studies from existing records or health care registers should be conducted to obtain data about the prevalence of low BMD and fractures in CRSwNP patients treated with glucocorticoids. This should be supplemented by a prospective evaluation of low BMD developing in patients with CRSwNP treated with glucocorticoids.

There seems to be no consensus on the doses and durations of steroids before preventive treatment should be initiated, and from the studies presented here, we know that they vary widely. Furthermore, it is unknown whether co-existing asthma affects the risk of osteoporosis. Studies have found adverse effects from doses as low as $2.5 \mathrm{mg}$ daily ${ }^{(5)}$ and there is no consensus about whether the daily or cumulative dose is the most important risk factor ${ }^{(13)}$. Future randomized controlled trials would be needed to identify the optimal doses of systemic steroids with respect to both treatment efficacy and osteoporosis. Furthermore, studies that compare side-effects of different systemic administrations of steroids in patients with CRSwNP are needed. Finally, it is necessary to determine the optimal preventive treatment in these patients: whether bisphosphonates, vitamin D or calcium should be used and in what combination.

\section{Conclusion}

Oral steroids with variable doses and durations administered in patients with nasal polyps with or without asthma were found to increase osteoporosis in the two included trials; however, we were unable to assess the risk of osteoporosis caused by oral steroids from these trials. We found no information on the effect of the preventive treatment.
It has been shown that doses of steroids commonly used for patients with CRSwNP can lead to an increased risk of osteoporosis as well as for osteopenia and fractures, while greater doses increase the risk substantially. However, it remains to be shown that this is valid for patients with CRSwNP. Until further trials have been presented we recommend that the general guidelines $(5,6,16,17)$ for glucocorticoid induced osteoporosis, not specifically related to CRSwNP should be used (Table 4), and that the recommended preventive treatments should be followed. There is limited information available about the risks associated with courses as short as 3-14 days and therefore we recommend that great attention should be paid to the risk of osteoporosis even in treatment with such short courses.

Randomized controlled trials, registry studies and prospective evaluations are needed to assess the risk of osteoporosis in CRSwNP patients treated with systemic steroids in combination with preventive treatments. In addition, future guidelines could include recommendations regarding preventive treatment measures in patients with CRSwNP treated with systemic steroids.

\section{Acknowledgements}

CGL is funded by The Candy's Foundation and Kræftfonden.

\section{Authorship contribution}

LW searched the scientific literature, extracted data and led the writing. All authors provided conceptual input, interpreted the findings, and contributed in significant ways to the final article.

\section{Conflict of interest}

The authors declare no conflicts of interest.

\section{References}

1. Mullol J, Obando A, Pujols L, Alobid I. Corticosteroid Treatment in Chronic Rhinosinusitis: The Possibilities and the Limits. Immunology and Allergy Clinics of North America 2009; 29(4): 657-668.

2. Scadding GK, Durham SR, Mirakian R et al. British Society for Allergy and Clinical Immunology. BSACI guidelines for the management of rhinosinusitis and nasal polyposis. Clin Exp Allergy. 2008; 38: 260-275.

3. Fokkens WJ, Lund VJ, Mullol J et al. EPOS 2012: European position paper on rhinosinusitis and nasal polyps 2012. Rhinology 2012; 50(1): 1-12

4. Nash JJ, Nash AG, Leach ME, Poetker DM. Medical malpractice and corticosteroid use. Official Journal of American Academy of Otolaryngology-Head and Neck Surgery 2011; 144(1): 10-15.

5. Bone and Tooth Society of Great Britain, National Osteoporosis Society, Royal College of Physicians. Glucocorticoidinduced osteoporosis: Guidelines for prevention and treatment. Royal College of
Physicians of London, Dec 2002.

6. National Osteoporosis Foundation Clinician's Guide to Prevention and Treatment of Osteoporosis. Washington, DC: National Osteoporosis Foundation; 2010: $1-36$.

7. Higgins JP, Green S, eds. Assessing risk of bias in included studies. Cochrane Handbook for Systematic Reviews of Interventions 2011; Version 5.1.0.

8. Rajasekaran K, Seth R, Abelson A, Batra PS. Prevalence of metabolic bone disease among chronic rhinosinusitis patients treated with oral glucocorticoids. American Journal of Rhinology and Allergy 2010; 24(3): 215-219.

9. Bonfils P, Halimi P, Malinvaud D. Adrenal suppression and osteoporosis after treatment of nasal polyposis. Acta OtoLaryngologica 2006; 126(11): 1195-1200.

10. Norès JM, Mutschler C, Malinvaud D, Halimt $P$, Bonfils P. Traitement médical de la polypose naso-sinusienne, Effet sur la densité minérale osseuse. La Presse Médicale 2005; 34: 1001-4.
11. US Department of Health and Human Services. Bone Health and Osteoporosis: A Report of the Surgeon General. Rockville, MD: US Department of Health and Human Services, Office of the Surgeon General; 2004

12. Matsumoto $H$, Ishihara $K$, Hasegawa $T$, Umeda B, Niimi A, Hino M. Effects of inhaled corticosteroid and short courses of oral corticosteroids on bone mineral density in asthmatic patients: a 4-year longitudinal study. Chest. 2001; 120(5): 1468-73.

13. Leib ES, Saag KG, Adachi JD et al. Official Positions for FRAX $\left.{ }^{\circledR}\right)$ clinical regarding glucocorticoids: the impact of the use of glucocorticoids on the estimate by $\operatorname{FRAX}\left({ }^{\circledR}\right)$ of the 10 year risk of fracture. Journal of Clinical Densitometry. 2011; 14(3): 212-9.

14. Van Staa TP, Laan RF, Barton IP, Cohen S, Reid DM, Cooper C. Bone density threshold and other predictors of vertebral fracture in patients receiving oral glucocorticoid therapy. Arthritis Rheum. 2003; 48(11): 3224-9.

15. Vestergaard $P$, Rejnmark L, Mosekilde L. Fracture risk associated with different types 
of oral corticosteroids and effect of termination of corticosteroids on the risk of fractures. Calcif Tissue Int. 2008; 82(4): 249-57.

16. Grossman JM, Gordon R, Ranganath VK, et al. American College of Rheumatology 2010 recommendations for the prevention and treatment of glucocorticoid-induced osteoporosis. Arthritis Care \& Research 2010; 62(11): 1515-1526

17. Vestergaard P, Schwarz P. Glucocorticoid induceret osteoporose. DKMS baggrundsartikel Dec. 2009. (Danish). Available from: http://wp.dkms.dk/wp content/uploads/2013/06/Baggrund_4a_ Epidemiologi.pdf.
Lisa Winblad, MD

Department of Otorhinolaryngology

Head and Neck Surgery and Audio-

logy

Copenhagen University Hospital

Rigshospitalet

Denmark

Tel.: +46730400364

E-mail: lisa_winblad@hotmail.com 